\title{
Detection of a highly prevalent and potentially virulent strain of Pseudomonas aeruginosa from nosocomial infections in a medical center
}

\author{
Ghassan M Matar*1, Mira H Chaar ${ }^{1}$, George F Araj ${ }^{3}$, Zaher Srour ${ }^{2}$, \\ Ghassan Jamaleddine ${ }^{4}$ and Usamah Hadi²
}

Address: ${ }^{1}$ Departments of Microbiology and Immunology, American University of Beirut, Beirut, Lebanon, ${ }^{2}$ Otolaryngology, Neck and Head Surgery, American University of Beirut, Beirut, Lebanon, ${ }^{3}$ Pathology and Laboratory Medicine, American University of Beirut, Beirut, Lebanon and ${ }^{4}$ Internal Medicine Faculty of Medicine, American University of Beirut, Beirut, Lebanon

Email: Ghassan M Matar* -gmatar@aub.edu.lb; Mira H Chaar - mira_chaar@yahoo.com; George F Araj - garaj@aub.edu.lb; Zaher Srour - uhadi@dm.net.lb; Ghassan Jamaleddine - ghassanj@aub.edu.lb; Usamah Hadi - uhadi@dm.net.lb

* Corresponding author

Published: 20 May 2005

BMC Microbiology 2005, 5:29 doi:10.1/86/147|-2180-5-29
Received: 26 January 2005

Accepted: 20 May 2005

This article is available from: http://www.biomedcentral.com/I47I-2/80/5/29

(c) 2005 Matar et al; licensee BioMed Central Ltd.

This is an Open Access article distributed under the terms of the Creative Commons Attribution License (http://creativecommons.org/licenses/by/2.0), which permits unrestricted use, distribution, and reproduction in any medium, provided the original work is properly cited.

\begin{abstract}
Background: We correlated genotypes, virulence factors and antimicrobial susceptibility patterns of nosocomially identified Pseudomonas aeruginosa isolates from clinical specimens to those of environmental isolates encountered in the same units of a medical center. Antibiotic susceptibility testing, RAPD analysis and detection of enzymatic activities of extracellular virulence factors, were done on these isolates.

Results: Data showed that most of the clinical and environmental isolates were susceptible to tested antimicrobial agents. RAPD analysis determined the presence of 31 genotypes, with genotype I detected in $42 \%$ of the clinical isolates and $43 \%$ of the environmental isolates. Enzymatic activity testing showed that genotype I produced all virulence factors tested for.

Conclusion: In conclusion, our data demonstrated the predominant prevalence of a potentially virulent $P$. aeruginosa genotype, circulating in a number of units of the medical center and emphasize the need to reinforce infection control measures.
\end{abstract}

\section{Background}

Despite the advances in hospital care and the introduction of a wide variety of antimicrobial agents, Pseudomonas aeruginosa continues to be a major nosocomial pathogen particularly in patients who suffer from immunosuppression [1]. P. aeruginosa is a ubiquitous pathogen prevalent in the hospital environments, and can cause severe nosocomial infections [2]. The latter involve a broad spectrum of infections including the respiratory, gastrointestinal, and urinary tracts as well as wound infections, sepsis and oth- ers [3]. Various possible sources of $P$. aeruginosa infection in hospitals have been identified; such as tap water, medical equipment, hospital personnel and other patients $[2,4]$. P. aeruginosa accounts for $10 \%$ of all hospital acquired infections, a site specific prevalence which may vary from one unit to another and from study to study [5]. Among data on site-specific infections, $P$. aeruginosa appears to be the major cause of ventilator-associated pneumonia with a high rate of attributable mortality [6]. Moreover this organism can contaminate a number of 
other medical equipment such as respirators, endoscopes, bronchoscopes, transvenous pacemakers, urinary catheters, and dialysis equipment, leading to site-related infections $[7,8]$. During the last year, the average prevalence of $P$. aeruginosa nosocomial infections in our medical center was $18 \%$. Such a high rate prompted us to study the P. aeruginosa genotypes circulating in the various units to reveal the clonal relationship between clinical and environmental isolates and to allow elucidating the source and mode of transmission of this important bacterium at this medical center.

\section{Results}

Our data have shown that several mechanical devices were associated with $P$. aeruginosa infection in our patients with $55 \%$ due to mechanical ventilation and the remaining $45 \%$ due to polysite catheters, Foley catheters and different types of surgery.

RAPD analysis have shown 31 genotypes present among the clinical and the environmental isolates (figure 1). Thirty eight of ninety $(42 \%)$ of the clinical isolates and $10 / 23(43 \%)$ of the environmental isolates showed genotype 1 to be distributed among the medical center units. Each of the genotypes 2-30 represented from 1-8\% of the strains. Antimicrobial susceptibility testing has shown that susceptibility patterns between clinical and environmental isolates were similar with most drugs showing > $90 \%$ susceptibility, with the exception of tobramycin and gentamycin which showed lower susceptibility $(83 \%)$ in the environmental strains. Data is in concordance with previous reports in this institution [13]. Enzymatic assays determined that genotype 1 in addition to other 10 genotypes, in clinical and environmental isolates, were positive for all virulence factors tested for. All other genotypes were all positive for the production of protease, lecithinase and coagulase and positive in $83-89 \%$ of the cases for the production of the other 4 virulence factors (Figure 2). Table 1 shows the relationship between the various genotypes, to source, antibiograms and virulence factors.

\section{Discussion}

The strain distribution based on RAPD analysis showed that clinical and environmental isolates distributed in one or more than one unit, included genotypes 1-8 and 9, with predominance of genotype 1 in all investigated units. This may indicate that cross contamination among patients lead to the spread of this genotype among the various units, possibly through transient hand carriage by health care personnel due to contact with contaminated surfaces or by patient contact with contaminated surfaces or medical equipment [4]. Our findings suggest that cross colonization may be an important means of $P$. aeruginosa spread and infection especially after identification of a potentially virulent clone (genotype 1) of this organism that had been propagated in various units over a period of 9 months. This could indicate that the patients were continuously infected with a strain originating from an exogenous source. The importance of cross colonization of $P$. aeruginosa in nosocomial infections was previously reported, by Bergmans et al who studied 100 patients admitted to an ICU ward; cross colonization accounted for $50 \%$ of all cases of acquired $P$. aeruginosa colonization, the other $50 \%$ of patients were probably colonized from endogenous sources [14].

The remaining genotypes were isolated exclusively from the clinical specimens of patients and were not detected among environmental isolates. Most of these genotypes did not harbor all the virulence factors tested for. Not being encountered in environmental sources may indicate that these strains may have been endogenously acquired. High rate of colonization with $P$. aeruginosa from endogenous sources occurs mainly in the respiratory and gastrointestinal tracts [2]. Hospitalization may lead to increased rates of carriage, particularly in the lower respiratory tract in patients undergoing mechanical ventilation, upper respiratory tract due to broncho- pulmonary colonization and infection, in the gastrointestinal tract of patients receiving chemotherapy for neoplastic diseases, or at virtually any site in patients treated with antibiotics $[3,15,16]$.

Prevalence of strains with resistance to all antimicrobial agents will constitute a major risk for hospitalized patients. In our study, though, the most prevalent strain of genotype 1 was susceptible to all antimicrobial agents and does not constitute a problem in treatment. However, its potential of producing all virulence factors and being spread by various means in the hospital, unlike other genotypes that harbor all virulence factors, may render genotype 1 a high risk pathogen specially in the immunosuppressed and debilitated patients. The fact that genotype 1 remained susceptible to all antibiotics lead to the conclusion that patients could be continuously infected with a strain originating from an exogenous source.

In addition to mechanical spread by personnel, this genotype may carry a number of adhesins that enhance its colonization in the hospital environment and render it more accessible to patients. Studies are underway in our laboratory to detect by PCR, genes encoding a number of adhesins and determine their transcription levels in genotype 1, in comparison to other encountered genotypes. This will shed light on the possible role of adhesins on the prevalence of this genotype in the hospital environment. The extracellular enzymes or toxins produced, on the other hand, will contribute to the breaking down physical barriers and help the organism to penetrate, impair host 

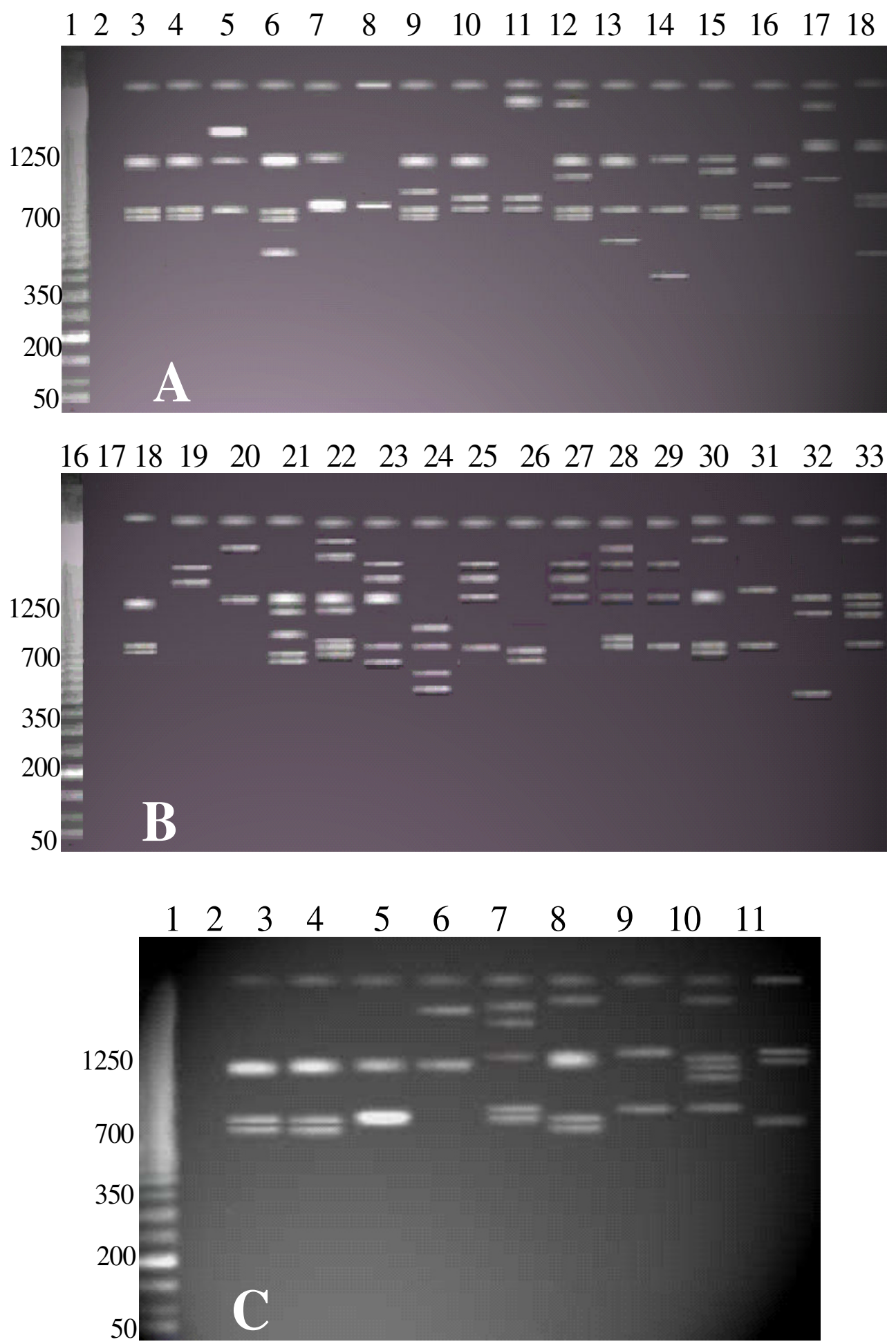

Figure I

(A) Genotypes of $P$. aeruginosa isolates found in 10 units. Lane I: 50-bp ladder, lane 2: negative control, lane 3:ATCC2532I strain, lanes 4-18: Genotypes I,2,3,4,5,6,7,8,9, I0, II, I2, I3, I4, and I5. (B) Lane 16: 50-bp ladder, lane I7: negative control, lane 18: ATCC 2532I strain, lanes 19-33: Genotypes 16, 17,18,19,20,21,22,23,24,25,26,27,28,29, and 30. (C) Genotypes of $P$. aeruginosa from environmental sources found in the RCU. Lane I: 50-bp ladder, lane 2: negative control, lane 3:ATCC 2532I strain, lane 4-II: Genotypes (I,4,I7,25,27,28,30,3I). 


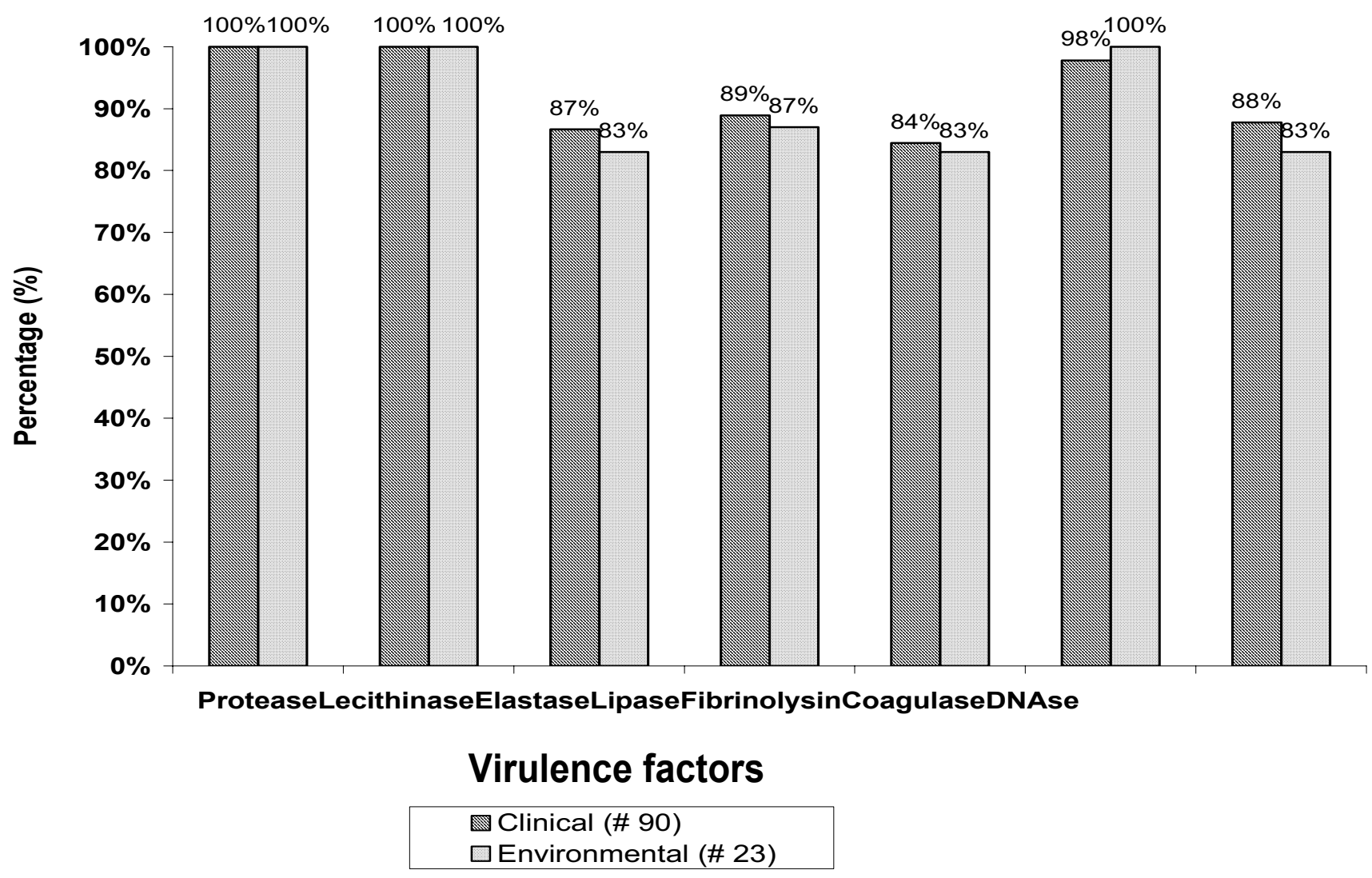

Figure 2

Percentage of clinical and environmental $P$. aeruginosa isolates producing the virulence factors.

defenses, and render its new milieu more conducive to its physical, nutritional and reproductive requirements [17].

In summary, our data have shown the predominant prevalence of a potentially virulent $P$. aeruginosa genotype 1 in clinical and environmental specimens, circulating in the various hospital units. From a practical point of view, the results of our study emphasize the need to reinforce implementation of infection control measures, and to limit the transmission of $P$. aeruginosa among patients and from environmental sources to patients. Screening for $P$. aeruginosa carriage in all patients with nosocomial colonization or infection should also be done in research settings using both rectal and respiratory tract specimens to determine the source of colonization/infection and hence get informed on whether it was acquired endogenously or exogenously.

\section{Conclusion}

In conclusion, our data have shown the predominant prevalence of a potentially virulent $P$. aeruginosa genotype
1 in clinical and environmental specimens, circulating in the various medical center units.

\section{Methods}

Consecutive $P$. aeruginosa (90) isolates were recovered from different patients specimens (one per patient) submitted for bacteriological investigations at the Clinical Microbiology Laboratory at the American University of Beirut Medical Center (AUBMC), between September 2003 and May 2004. Patients acquiring a nosocomial infection due to $P$. aeruginosa as determined by clinical and laboratory testing and indicated in their medical records, were only considered in this study. Fever, and recovery of $P$. aeruginosa from the site of infection during stay at the medical center, constituted the most important criteria that defined patient's infection with this organism. Patients' data collected from the medical records, included age ( 2 to 91 years), sex (Males: 43 and Females: 47), admission date, admission diagnosis, invasive procedures used on the patients, symptoms, and the date of the first positive culture for $P$. aeruginosa. The drugs used in the treatment of these patients, mainly included: 
Table I: Correlation between $P$. aeruginosa genotypes, source and site of infection, antimicrobial susceptibility and enzymatic activities of virulence factors

\begin{tabular}{|c|c|c|c|c|c|c|c|c|c|c|c|c|c|c|c|c|c|}
\hline \multirow[t]{2}{*}{ Genotypes } & \multirow{2}{*}{$\begin{array}{l}\text { types of } \\
\text { unit }\end{array}$} & \multirow{2}{*}{$\begin{array}{l}\text { Number of } \\
\text { clinical } \\
\text { isolates }\end{array}$} & \multirow{2}{*}{$\begin{array}{c}\text { Isolation } \\
\text { site/ } \\
\text { Number of } \\
\text { isolates }\end{array}$} & \multicolumn{9}{|c|}{ Antibiograms } & \multicolumn{5}{|c|}{ Virulence factors } \\
\hline & & & & AN & ATM & CAZ & CIP & GM & IPM & $\mathrm{TZ}$ & NN & Pro & Lec & Elas & Lip & Fib & Coag \\
\hline \multirow[t]{9}{*}{1} & $\mathrm{RCU}$ & 15 & $\begin{array}{l}\text { DTA'/ I I } \\
\text { blood/ I } \\
\text { Wound/ I }\end{array}$ & $\mathrm{S}$ & $\mathrm{S}$ & $\mathrm{S}$ & S & $S$ & $S$ & S & $S$ & + & + & + & + & + & + \\
\hline & $\mathrm{ICU}$ & 3 & $\begin{array}{c}\text { DTA/ } 2 \\
\text { Wound/ I }\end{array}$ & $\mathrm{S}$ & $\mathrm{S}$ & $S$ & $\mathrm{~S}$ & $S$ & $S$ & $S$ & $S$ & + & + & + & + & + & + \\
\hline & $\mathrm{CCU}$ & I & Urine/ I & $\mathrm{S}$ & $\mathrm{S}$ & $\mathrm{S}$ & S & S & S & S & $\mathrm{S}$ & + & + & + & + & + & + \\
\hline & $\mathrm{PICU}$ & 4 & $\begin{array}{c}\text { DTA/2 } \\
\text { Tongue/ I } \\
\text { Wound/ I }\end{array}$ & $\mathrm{S}$ & $\mathrm{S}$ & $\mathrm{S}$ & $\mathrm{S}$ & S & S & $S$ & $\mathrm{~S}$ & + & + & + & + & + & + \\
\hline & St Jude & 1 & Wound/ I & $\mathrm{S}$ & $\mathrm{S}$ & $\mathrm{S}$ & S & S & $S$ & $S$ & $\mathrm{~S}$ & + & + & + & + & + & + \\
\hline & Surgery & 3 & Wound/ 3 & $S$ & $S$ & $S$ & $S$ & $S$ & $S$ & $S$ & $S$ & + & + & + & + & + & + \\
\hline & 5 South & 6 & $\begin{array}{c}\text { Abscess/ I } \\
\text { Sputum/ } 2 \\
\text { DTA/ I } \\
\text { Bronchial } \\
\text { washing/ I } \\
\text { Urine/ I }\end{array}$ & $S$ & $S$ & $S$ & $S$ & $S$ & $S$ & $S$ & $S$ & + & + & + & + & + & + \\
\hline & 4 South & 2 & $\begin{array}{l}\text { Sputum/ I } \\
\text { Swab/ I }\end{array}$ & $S$ & $S$ & $S$ & $S$ & $S$ & $S$ & $S$ & $S$ & + & + & + & + & + & + \\
\hline & 9 South & 3 & $\begin{array}{l}\text { DTA/ I } \\
\text { Sputum/ I } \\
\text { Blood/ I }\end{array}$ & $S$ & $S$ & $S$ & $S$ & $S$ & $S$ & $S$ & $S$ & + & + & + & + & + & + \\
\hline \multirow[t]{5}{*}{2} & $\mathrm{RCU}$ & I & DTA/ I & $S$ & $S$ & $\mathrm{~S}$ & $S$ & $S$ & $S$ & $S$ & $S$ & + & + & + & + & + & + \\
\hline & ICU & 1 & DTA/ I & $S$ & $S$ & $S$ & $S$ & $S$ & $S$ & $S$ & $S$ & + & + & + & + & + & + \\
\hline & Surgery & 2 & Wound/ 2 & $S$ & $S$ & $S$ & $S$ & $S$ & $S$ & $S$ & $S$ & + & + & + & + & + & + \\
\hline & Oncology & 1 & Blood/ I & $S$ & $S$ & $S$ & $S$ & $S$ & $S$ & $S$ & $S$ & + & + & + & + & + & + \\
\hline & 5 south & $\mathrm{I}$ & Pleural fuild/ & $S$ & $S$ & $S$ & $S$ & $S$ & $S$ & $S$ & $S$ & + & + & + & + & + & + \\
\hline \multirow[t]{3}{*}{3} & $\mathrm{RCU}$ & 2 & $\begin{array}{c}\text { DTA/ I } \\
\text { Wound/ I }\end{array}$ & $\mathrm{S}$ & $S$ & $\mathrm{~S}$ & $S$ & $S$ & $S$ & $S$ & $S$ & + & + & + & + & + & + \\
\hline & 5 South & 2 & Sputum/ 2 & $S$ & $S$ & $S$ & $S$ & $S$ & $S$ & $S$ & $S$ & + & + & + & + & + & + \\
\hline & Oncology & 3 & $\begin{array}{l}\text { DTA/ } 2 \\
\text { Blood/ I }\end{array}$ & $\mathrm{S}$ & $S$ & $\mathrm{~S}$ & $\mathrm{~S}$ & S & $S$ & S & $\mathrm{S}$ & + & + & + & + & + & + \\
\hline \multirow[t]{3}{*}{4} & $\mathrm{RCU}$ & 1 & DTA/ I & $\mathrm{S}$ & $S$ & $S$ & $S$ & $S$ & $S$ & $S$ & $S$ & + & + & + & + & + & + \\
\hline & St Jude & 2 & $\begin{array}{c}\text { Blood/ I } \\
\text { Catheter/ I }\end{array}$ & $S$ & $S$ & $S$ & $S$ & $S$ & $S$ & $S$ & $S$ & + & + & + & + & + & + \\
\hline & 5 South & 1 & Bile/ I & $\mathrm{S}$ & $S$ & $S$ & $S$ & $S$ & $S$ & $S$ & $S$ & + & + & + & + & + & + \\
\hline \multirow[t]{2}{*}{5} & PICU & I & DTA/ I & $\mathrm{S}$ & $S$ & $\mathrm{~S}$ & S & S & $S$ & S & S & + & + & - & + & + & + \\
\hline & 4 South & I & DTA/ I & $\mathrm{S}$ & $S$ & $\mathrm{~S}$ & $\mathrm{~s}$ & $\mathrm{~S}$ & S & $\mathrm{s}$ & S & + & + & - & + & + & + \\
\hline \multirow[t]{2}{*}{6} & $\mathrm{RCU}$ & 1 & DTA/ I & $S$ & $S$ & $S$ & $S$ & $S$ & $S$ & $S$ & $S$ & + & + & + & - & + & + \\
\hline & ICU & 1 & Sinus/ I & $\mathrm{s}$ & $\mathrm{s}$ & $\mathrm{s}$ & $\mathrm{s}$ & S & $S$ & $S$ & S & + & + & + & - & + & + \\
\hline \multirow[t]{2}{*}{7} & ICU & 2 & DTA/ 2 & $S$ & $S$ & $S$ & $S$ & $S$ & $S$ & $S$ & $S$ & + & + & + & - & + & + \\
\hline & Oncology & 1 & Blood/ I & $S$ & $S$ & $S$ & $S$ & $S$ & $S$ & $S$ & $S$ & + & + & + & - & + & + \\
\hline \multirow[t]{2}{*}{8} & ICU & 1 & DTA/ I & $\mathrm{s}$ & $\mathrm{S}$ & $\mathrm{s}$ & $\mathrm{s}$ & $\mathrm{s}$ & $\mathrm{s}$ & $S$ & $\mathrm{~s}$ & + & + & + & + & - & + \\
\hline & Oncology & 1 & Blood/ I & $S$ & $S$ & $S$ & $S$ & $S$ & $S$ & $S$ & $S$ & + & + & + & + & - & + \\
\hline \multirow[t]{2}{*}{9} & $\mathrm{RCU}$ & 1 & Urine/ I & $\mathrm{S}$ & $\mathrm{S}$ & $\mathrm{S}$ & $\mathrm{S}$ & $S$ & $S$ & $S$ & $\mathrm{~S}$ & + & + & + & + & + & + \\
\hline & Surgery & 1 & Wound/ I & $\mathrm{s}$ & $\mathrm{S}$ & $\mathrm{S}$ & $\mathrm{S}$ & $\mathrm{s}$ & $S$ & $\mathrm{~S}$ & $\mathrm{~S}$ & + & + & + & + & + & + \\
\hline 10 & 4 South & 2 & Wound/ 2 & $S$ & $S$ & $S$ & $\mathbf{R}$ & $\mathbf{R}$ & $\mathbf{R}$ & $\mathbf{R}$ & $\mathbf{R}$ & + & + & - & + & - & + \\
\hline 11 & Oncology & 2 & $\begin{array}{l}\text { leg ulcer/ I } \\
\text { Bronchial } \\
\text { washing/ I }\end{array}$ & $S$ & $S$ & $S$ & $\mathrm{~S}$ & $\mathrm{~S}$ & $\mathrm{~s}$ & $\mathrm{~S}$ & $\mathrm{~S}$ & + & + & + & + & + & + \\
\hline 12 & 5 South & 2 & DTA/ 2 & $S$ & $S$ & $\mathrm{~S}$ & $S$ & $\mathrm{~S}$ & $S$ & $S$ & $S$ & + & + & + & - & - & + \\
\hline 13 & 9 South & 1 & $\begin{array}{c}\text { Sinus } \\
\text { discharge/ I }\end{array}$ & $\mathrm{S}$ & $S$ & $S$ & $\mathbf{R}$ & $\mathbf{R}$ & $S$ & $S$ & $\mathbf{R}$ & + & + & - & + & - & + \\
\hline 14 & 9 South & 1 & Wound/ I & $S$ & $S$ & $S$ & S & $S$ & $S$ & $S$ & $S$ & + & + & + & + & + & + \\
\hline 15 & ICU & I & DTA/ I & $S$ & $S$ & $S$ & $S$ & $S$ & $S$ & $S$ & $S$ & + & + & + & - & + & + \\
\hline
\end{tabular}


Table I: Correlation between $P$. aeruginosa genotypes, source and site of infection, antimicrobial susceptibility and enzymatic activities of virulence factors (Continued)

\begin{tabular}{|c|c|c|c|c|c|c|c|c|c|c|c|c|c|c|c|c|c|}
\hline 16 & $\mathrm{CCU}$ & $T$ & $\begin{array}{c}\text { Sternal } \\
\text { tissue / I }\end{array}$ & $\mathrm{S}$ & $\mathrm{S}$ & $\mathrm{S}$ & $\mathrm{S}$ & $\mathrm{S}$ & $\mathrm{S}$ & $\mathrm{S}$ & $\mathrm{S}$ & + & + & + & + & + & - \\
\hline 17 & $\mathrm{CCU}$ & I & Urine/ I & $S$ & $S$ & $S$ & $S$ & $S$ & $S$ & $S$ & $S$ & + & + & + & - & + & + \\
\hline 18 & $\mathrm{CCU}$ & I & DTA/ I & $S$ & I & $S$ & $S$ & $\mathrm{~S}$ & $S$ & $S$ & $S$ & + & + & - & - & - & + \\
\hline 19 & $\mathrm{RCU}$ & I & DTA/ I & $S$ & I & $S$ & $S$ & $S$ & $S$ & $S$ & $S$ & + & + & + & + & + & + \\
\hline 20 & $\mathrm{RCU}$ & I & DTA/ I & $S$ & $S$ & $S$ & $S$ & $S$ & $\mathbf{R}$ & $S$ & $S$ & + & + & - & + & - & + \\
\hline 21 & $\mathrm{RCU}$ & I & DTA/ I & $S$ & $S$ & $S$ & $S$ & $\mathbf{R}$ & $\mathrm{S}$ & $S$ & $\mathbf{R}$ & + & + & - & + & - & + \\
\hline 22 & $\mathrm{RCU}$ & I & DTA/ I & $S$ & I & $S$ & $S$ & $S$ & $S$ & $S$ & $S$ & + & + & + & + & + & + \\
\hline 23 & $\mathrm{RCU}$ & I & DTA/ I & $S$ & I & $\mathrm{S}$ & $S$ & $S$ & $S$ & $\mathbf{R}$ & $S$ & + & + & - & + & - & + \\
\hline 24 & $\mathrm{RCU}$ & I & Wound/ I & $\mathbf{R}$ & $\mathrm{S}$ & $\mathbf{R}$ & $\mathbf{R}$ & $\mathbf{R}$ & $\mathbf{R}$ & $\mathbf{R}$ & $\mathbf{R}$ & + & + & - & + & - & + \\
\hline 25 & $\mathrm{RCU}$ & I & DTA/ I & $S$ & $S$ & $S$ & $S$ & $\mathbf{R}$ & $S$ & $S$ & I & + & + & + & + & + & + \\
\hline 26 & $\mathrm{RCU}$ & I & Sputum/ I & $S$ & $\mathbf{R}$ & $\mathbf{R}$ & $S$ & $S$ & $\mathbf{R}$ & $\mathbf{R}$ & $S$ & + & + & - & + & - & + \\
\hline 27 & $\mathrm{PICU}$ & I & DTA/ I & $S$ & $\mathbf{R}$ & $\mathbf{R}$ & $S$ & $S$ & $S$ & $\mathbf{R}$ & $S$ & + & + & + & + & + & + \\
\hline 28 & ICU & I & DTA/ I & $S$ & $\mathbf{R}$ & $\mathbf{R}$ & $S$ & $S$ & I & $\mathbf{R}$ & $S$ & + & + & + & + & + & + \\
\hline 29 & 4 South & I & DTA/ I & $S$ & I & $\mathrm{S}$ & $S$ & $\mathbf{R}$ & $\mathbf{R}$ & $\mathrm{S}$ & $S$ & + & + & + & + & + & - \\
\hline 30 & RCU & I & DTA/ I & $S$ & $S$ & $S$ & $S$ & $\mathbf{R}$ & $S$ & $S$ & I & + & + & - & + & - & + \\
\hline
\end{tabular}

NB: Genotype 31 was only found among the environmental isolates

I DTA: Deep Tracheal Aspirate

AN: Amikacin

CIP: Ciprofloxacin

TZ: Tazocin

ATM: Aztreonam

GM: Gentamicin

NN: Tobramycin

CAZ : Ceftazidime

IPM: Imipenem

Pro: Protease

Lip: Lipase

Lec: Lecithinase

Fib: Fibrinolysin

Elas: Elastase

Coag: Coagulase

amikacin, azactam, gentamicin, tobramycin, and tazocin. Patients were distributed within ten different units in the medical center, mainly the Respiratory Care Unit (RCU), Intensive Care Unit (ICU), Coronary Care Unit (CCU), the Surgery Unit, as well as other units. Twenty three isolates were also collected from different environmental sources, such as, respirators, respirators' filters, water irrigation, tap water, basins, trays, bed side tables, side rails, and sink sides. Statistical analysis determined the sample size required to estimate the true proportion (percentage of $P$. aeruginosa infections during a given period of time) to within 0.10 , with $95 \%$ confidence was calculated. Calculations estimated the minimum number of samples required to be 54 [9].

The presumptive identification of $P$. aeruginosa on culture based on colonial morphology, Gram stain microscopy, and oxidase test was further confirmed by the API NE Kits and growth at $42^{\circ} \mathrm{C}$. Susceptibility of all isolates to a panel of antimicrobial agents (amikacin, aztreonam, ceftazidime, ciprofloxacin, gentamicin, imipenem, piperacillin/tazobactam, tobramycin) was determined according to the guidelines of the National Committee for
Clinical Laboratory Standards (NCCLS) [10]. P. aeruginosa ATCC 25321 strain was used as positive control in all tests.

DNA was extracted from $P$. aeruginosa ATCC strain and from all isolates of $P$. aeruginosa by the $\mathrm{GFX}^{\mathrm{TM}}$ Genomic Blood DNA Purification Kit (Amersham PharmaciaBiotech, Uppsala, Sweden) according to the manufacturers' specifications. Random amplified polymorphic DNA (RAPD) analysis of the clinical and environmental isolates using two in-house oligonucleotide primers, $\mathrm{Pa} 1$ (5'AGGGGTCTTG 3') and Pa2 (5' CTTCTTCAGCTCGACGCGACG 3') was done. RAPD was carried out according to Matar et al [11] using the PTC-100 ${ }^{\mathrm{TM}}$ Programmable Thermal Controller (MJ Research, Inc., Watertown, Mass., USA). Briefly, RAPD was carried out on all isolates in $100 \mu \mathrm{l}$ reaction mixtures containing each: $10 \mu \mathrm{l}$ of template DNA, $16 \mu \mathrm{l}$ of dNTPs $(0.2 \mathrm{mM}), 10 \mu \mathrm{l}$ of $10 \mathrm{X}$ PCR buffer (100 mM TrisHCl [pH 8.3], $500 \mathrm{mM} \mathrm{KCl,} 4$ $\left.\mathrm{mM} \mathrm{MgCl}{ }_{2}\right), 1 \mu \mathrm{l}$ of primer $1(0.5 \mu \mathrm{M}), 1 \mu \mathrm{l}$ of primer 2 $(0.3 \mu \mathrm{g} / \mu \mathrm{l}), 2.5 \mathrm{U}$ of Taq DNA polymerase and $61.5 \mu \mathrm{l}$ of nanopure sterile water. The amplification program, included the following steps: denaturation at $94^{\circ} \mathrm{C}$ for $3 \mathrm{~s}$, 
annealing at $53^{\circ} \mathrm{C}$ for $1 \mathrm{~min}$ and extension at $72^{\circ} \mathrm{C}$ for 1 min, for 44 cycles. The cycles were followed by a final extension step at $72^{\circ} \mathrm{C}$ for $10 \mathrm{~min}$. Amplicons were subjected to electrophoresis on $2 \%$ agarose gels at 107 volts for 2 hours. Patterns that had the same number of bands and similar fragments size were considered identical.

The enzymatic activities of the isolates of $P$. aeruginosa were evaluated by spot inoculation containing $10^{6} \mathrm{CFU} /$ $\mathrm{ml}$ of the organisms in various media [12]. Media used: Brain heart infusion for the protease activity, 1\% elastin (Sigma Chemical Co. St Louis, Mo. USA) for the elastase activity, human fibrinogen type 1 (Sigma Chemical Co. St Louis, Mo. USA) for the fibrinolytic activity, trypticase soy agar (TSA) supplemented with egg yolk (Difco Laboratories, Detroit, Mi., USA) for the lecithinase production, TSA with tween 80 (Sigma Chemical Co. St Louis, Mo. USA) for the lipase activity, DNase test agar with toluidine blue 0, (Difco Laboratories, Detroit Mi., USA) for the DNAase production, and rabbit plasma (Difco Laboratories, Detroit Mi., USA) for the coagulase activity. Positivity of tests was assessed as follows: clearing of opacity around the inoculum spots for the protease, elastase and fibrinolytic activities, white precipitate around or beneath the inoculum spots for the lecithinase activity, a turbid halo around the inoculum spots for the lipase activity, formation of a pink halo around the inoculum spots for the DNase activity, and gelling of rabbit plasma after 48 hours for the coagulase activity.

\section{Authors' contributions}

GM supervised the study and wrote the manuscript. MC did the bench work and helped in writing the manuscript. GA provided bacterial isolates. ZS provided help on wards. GJ provided clinical support. UH provided clinical support. All authors read and approved the final manuscript.

\section{Acknowledgements}

Thanks are due Miss Marie Risk and Mr. Elias Rahal for technical assistance.

\section{References}

I. Zenone T, Souillet G: $\mathbf{X}$ linked Agammaglobulinemia presenting as Pseudomonas aeruginosa septicemia. Scand J Infect Dis 1996, 28:417-418.

2. Morrison AJ, Wenzel RP: Epidemiology of infections due to Pseudomonas aeruginosa. Rev Infect Dis 1984, 6:S627-S642.

3. Pollack M: Pseudomonas aeruginosa. In Principles and Practice of infectious diseases Edited by: Mandell GL, Bennett JE, Dolin R. New York: Churchill Livingstone; 1995:1980-2003.

4. Pittet D, Dharan S, Touveneau S, Sauvan V, Perneger TV: Bacterial contamination of the hands of hospital staff during routine patient care. Arch Intern Med 1999, I 59:82I-826.

5. Jones RN, Croco MA, Kugler KC, Pfaller MA, Beach ML: Respiratory tract pathogens isolated from patients hospitalized with suspected pneumonia: frequency of occurrence and susceptibility patterns from the Sentry Antimicrobial Surveillance Program. Diagn Microbiol Infect Dis 2000, 37:I I5-125.

6. Rello J, Rue M, Jubert $P$ : Survival in patients with nosocomial pneumonia: impact of the severity of illness and the etiologic agent. Crit Care Med 1997, 25:1862-1867.
7. Baker AM, Meredith JW, Gontijo PP: Pneumonia in intubated trauma patients-microbiology and outcomes. Am J Respir Crit Care Med 1996, 153:343-347.

8. Morrison AJ, Wenzel RP: Epidemiology of infections due to Pseudomonas aeruginosa. Rev Infect Dis 1984, 6:S627-S642.

9. Kuzma JW: Determination of sample size. Kuzma, JW. In Basics statistics for the health sciences Edited by: Kuzma JW. California: Mayfield Publishing Company; 1998:117-II8.

10. National Committee for Clinical Laboratory Standards: Performance standards for antimicrobial susceptibility testing; Fourteenth informational supplement. NCCLS document M 100- SI 4. National Committee for Clinical Laboratory Standards, Wayne, Pennsylvania, USA 2004:36-37.

II. Matar, GM Harakeh HS, Ramlawi F, Khneisser I, Hadi U: Comparative analysis between Pseudomonas aeruginosa genotypes and severity of symptoms in patients with unilateral or bilateral otits externa. Curr Microbiol 200I, 42:190-193.

12. Matar GM, Ramlawi F, Harakeh HS, Hadi U: Comparative Analysis Between Virulence Factors Produced By Various Pseudomonas aeruginosa Genotypes and Severity of Symptoms in Patients with Otitis Externa. Br Med J (ME) 2002, 9:7-9.

13. Araj G, Kanj S: Current status and changing trends of antimicrobial resistance in Lebanon. J Med Liban 2000, 48:22I-226.

14. Bergmans DC, Bonten MJ, Vantiel FH, Gaillard CA, Van der Geest S, Wilting RM, De Leeuw PW, Stobberingh EE: Cross colonization with Pseudomonas aeruginosa of patients in an intensive care unit. Thorax 1998, 53:1053-1058.

15. Berthelot P, Grattard F, Mahul P, Pain P, Jospe R, Venet C, Carricajo A, Aubert G, Ros A, Dumont A, Lucht F, Zeni F, Auboyer C, Bertrand $J$-C, Pozzetto B: Prospective study of nosocomial colonization and infection due to Pseudomonas aeruginosa in mechanically ventilated patients. Int Care Med 200I, 27:503-5I2.

16. Correa CMC, Tibana A, Gontijo Filho PP: Vegetables as a source of infection with Pseudomonas aeruginosa Vin a university and oncology hospital of Rio de Janeiro. J Hosp Infect 1991, 18:30I-306.

17. Amitani R, Wilson R, Rutman A: Effects of human neutrophil elastase and pseudomonas aeruginosa proteinases on human respiratory epithelium. Am J Respir Cell Mol Biol |99|, 4:26-32.

\section{Publish with Biomed Central and every scientist can read your work free of charge}

"BioMed Central will be the most significant development for disseminating the results of biomedical research in our lifetime. "

Sir Paul Nurse, Cancer Research UK

Your research papers will be:

- available free of charge to the entire biomedical community

- peer reviewed and published immediately upon acceptance

- cited in PubMed and archived on PubMed Central

- yours - you keep the copyright

Submit your manuscript here:

http://www.biomedcentral.com/info/publishing_adv.asp
BioMedcentral 